\title{
APPLICATION OF THE RESPONSE SURFACE METHODOLOGY IN A POSTGRADUATE OPTIMIZATION COURSE
}

\author{
V. Yepes, D. Martínez-Muñoz, J.V. Martí \\ ICITECH. Dept. Ingeniería de la Construcción y Proyectos de Ingeniería Civil. Universitat \\ Politècnica de València (SPAIN)
}

\begin{abstract}
This paper describes the introduction of response surface methodology in a postgraduate course. This case study is carried out in the subject of the predictive models of optimization of concrete structures subject. This subject is inside the curricula of concrete engineering master. In this course students learn concepts such as structures' optimization using algorithms, multi-criteria decision making, techniques do design of experiments, and metamodels such as the response surface in order to obtain optimum results. In this case study, the objective is to obtain a design solution of a reinforced concrete wall, using the $\mathrm{CO}_{2}$ emissions as an objective function to reduce its impact. In order to apply this methodology, the students need to use specific software. On the one hand, to carry out the statistical analysis that allow obtaining the response surface Minitab software has been used by students. On the other hand, students need to check the strength of the structure using Cype structural calculation software. As a result of applying this methodology to obtain an optimum reinforced concrete wall allow students to reach a better level in transversal competencies, such as design and project, critical thinking, analysis and problem solving or the use of specific software. This paper will introduce future research studies related to the use of structures optimization techniques by students applying other different optimization techniques.
\end{abstract}

Keywords: response surface, engineering, transversal skills, optimization, postgraduate education.

\section{INTRODUCTION}

\subsection{Postgraduate studies in the engineering field}

Engineering university European studies are characterized by providing training in a large number of areas. Particularly, Spanish Civil Engineering studies cover all fields related to the infrastructures that involve the profession. These fields range from the design and construction of roads, to dimensioning of structures such as bridges or dams. This leads to a generalist training of engineers, and usually this training needs to be complemented by postgraduate studies. These courses are focused on every area of study in a more specific way. The Universitat Politècnica de València has a large number of these masters' studies. Among them, is the Master in Concrete Engineering that also has the EUR-ACE label, which ensures a good quality of these studies. The purpose of this work is the presentation of the subject "predictive models and structural concrete optimization", since it provides knowledge that connects the world of research with the world of teaching like it have been seen in other works [1]-[6].

\subsection{Background}

Teaching in the Civil Engineering area of knowledge is based on the transmission of technical skills. These skills are linked to the calculation and design of the different infrastructures. In accordance with this type of teaching, the student is told that the best infrastructure is the one that uses the least possible resources to fulfil the function for which it is intended. This concept of teaching, that has traditionally been used, was based mainly on cost reduction. This search for the reduction of resources is basically a sweep of the optimum infrastructure. This process is called in research field optimization and it is closely linked to infrastructures project.

The traditional design of infrastructures is done through an iterative procedure based on an initial predimensioning and a subsequent verification. In every iteration, the designer try to reduce the cost of the infrastructure. Therefore, the effectiveness of this process is based primarily on the experience of the designer, because simply with technical knowledge, technicians are not able to easily reach a good solution. This approach to optimization was valid when there were no tools that allowed an automatic search for solutions due to their high cost. Nowadays, technology allows us to have powerful tools that 
are available to anyone and, therefore, this method is becoming obsolete. Besides that, the objective is to reduce the structures' cost, and consequently, the method avoid other criteria such as the environmental or social impact among others. The current optimization objective has changed, tending towards solutions that allow sustainable development [7] and turned to look for considering several alternatives involving the environmental and social impacts [8].

Due to the changing focus on society's needs and the emergence of powerful computer tools has led to a change in teaching needs. Moreover, this is where the subject predictive models and structural concrete optimization fits in. This subject introduces optimization to students using different methods in order to apply heuristic, metaheuristic and metamodels optimization. All these methods are applied to obtain optimal structures. In this case study, it has been applied to the optimization of concrete walls.

Walls are one of the most used structures in the field of civil and building engineering. The optimization of this type of structures allows them to be carried out in a more economical or environmentally friendly way depending on the objective of the optimization. Therefore, different works have been carried out related to the optimization of this type of structures either in terms of cost [9], [10], CO2 emissions [11] or comparing the differences between the optimization of both optimization objectives [12]. In some research works, the typology of retaining walls has been analyzed evaluating their life cycle [13], [14] comparing the different types of wall according to their impact. In addition, this impact approach has been used to carry out the optimization of other types of structures [15].

Obtaining optimal solutions is a procedure that need to calculate solutions in order to compare the different results between them. To ensure the global optimum, the only possibility is the use of mathematical programming methods [16] but these becomes unfeasible for complex problems due to the exponential growth of calculation time with the increase in the number of variables. This limitation explains the success of heuristic algorithms [17], which despite not ensuring the achievement of an overall optimum to the problem, consume much less time, making them an option for optimizing competitive structures. Among the most used heuristics, we can highlight the genetic algorithms [18], the simulated annealing [19]-[22], the neuronal networks [23], [24], or the swarm optimization [25]-[27]. However, there are many types of heuristic algorithms available uses in structures. Some authors have compiled exhaustive lists of optimization heuristics [28], and because of this some authors have compiled which algorithms have been used in specific cases such as certain types of structures [29]. Usually, surrogate models or metamodels are not included in that lists. In fact, metamodels simplify some problems presented by direct optimization such as multiple local optimizations, multiple objectives and limitations of design and/or response parameters. This feature is explained by the change of the stochastic response, by another deterministic type [30]. Several studies have been carried out in which the authors have used metamodels to optimize a problem according to different objectives [31], [32]. Among the metamodels is the response surface methodology, applied for the first time to study the optimal operating conditions in a chemical process [33]. Subsequently it has been applied in other fields [34], [35]. In a tight synthesis, the response surface strategy consists in studying a delimited region and looking for new regions that are increasingly close to the optimum.

In this paper, a reinforced concrete wall is optimized in a classroom case study. Students have used an experiment design and the response surface methodology is order to reach an optimum solution. For this purpose, students have used the experiment design in order to locate the most significant ones to consider these for the optimization procedure. Then, a region of the space delimited by means of a first order response surface is studied and the method of fast ascent/descent is applied. To approach the environment of the local optimum they done movement in the direction of the line of maximum slope. Finally, a second order response surface is applied in the region near the optimum to determine the final value. This procedure not only gives the student one tool to get an optimum solution, but also forces him to use both statistical and calculation tools in order to arrive to the solution.

On the one hand, the software used to do the structural and stability checks of the walls is the commercial software CYPE [26]. On the other hand, the designs of experiments and the methodology of the response surface have been carried out through the Minitab program [27]. In addition, Excel spreadsheets have been used to obtain the corresponding measurement. As a result of applying this methodology to obtain an optimum reinforced concrete wall. Students have been able to to acquire different transversal competencies, such as design and project, critical thinking, analysis and problem solving or the use of specific instrumental. These gives an added value to students who have studied the master's degree in concrete engineering. 


\section{STRUCTURAL MODEL DESCRIPTION}

The structure to be optimized is a five-meter high earth retaining wall shown in Figure 1 . To do this, the structure is defined according to its geometric variables.

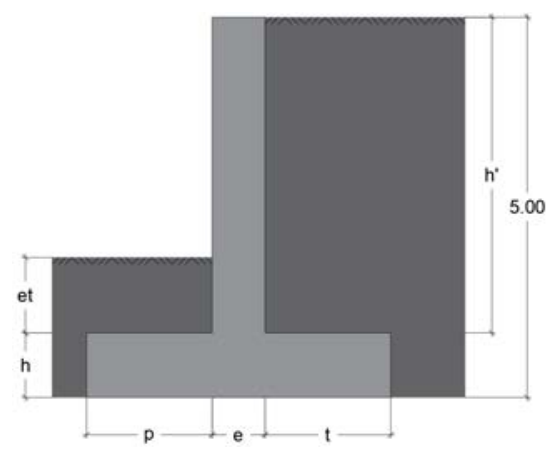

Figure 1. Diagram of the retaining wall and geometric variables.

Table 1 defines the two levels studies for each variable. Table 2 shows the parameters that define the soils characteristics, materials and safety coefficients taken into account in the calculation structures' calculation.

Table 1. Geometric variables and levels.

\begin{tabular}{cllcc}
\hline \multirow{2}{*}{ Variable } & \multirow{2}{*}{ Unit } & \multicolumn{2}{c}{ Description } & \multicolumn{2}{c}{ Levels } \\
\cline { 4 - 5 } & & & - & + \\
\hline $\mathrm{e}$ & $\mathrm{cm}$ & Stem thickness & 30 & 150 \\
$\mathrm{p}$ & $\mathrm{cm}$ & Toe Length & 100 & 250 \\
$\mathrm{t}$ & $\mathrm{cm}$ & Heel Length & 100 & 250 \\
$\mathrm{~h}$ & $\mathrm{~cm}$ & Footing thickness & 50 & 150 \\
$\mathrm{et}$ & $\mathrm{cm}$ & Earth thickness at intrados & 0 & 200 \\
\hline
\end{tabular}

Table 2. Definition of soil parameters, materials and safety coefficients.

\begin{tabular}{lcc}
\hline \multicolumn{1}{c}{ Parameter } & Unit & Value \\
\hline Materiales & & \\
Concrete & $\mathrm{HA}-30 / \mathrm{B} / 30 / \mathrm{lla}$ \\
Concrete safety coefficient & 1.5 \\
Steel & $\mathrm{B} 500 \mathrm{~S}$ \\
Steel safety coefficient & 1.15 \\
Coating & & \\
Trasdos and Intrados & $\mathrm{mm}$ & 30 \\
Upper and Lower of Footing & $\mathrm{mm}$ & 50 \\
Footing sides & $\mathrm{mm}$ & 70 \\
Soil & & \\
Apparent density & $\mathrm{kN} / \mathrm{m} 3$ & 18 \\
Friction angle & $\circ$ & 30 \\
Cohesion & $\mathrm{t} / \mathrm{m} 2$ & 0 \\
Thrust in the back & & Pasive \\
Thrust in the front & & Active \\
Permissible stress & $\mathrm{MPa}$ & $0.5 \mathrm{MPa}$ \\
Friction coefficient at the base & & 0.6 \\
\hline
\end{tabular}




\section{METHODOLOGY}

The method used to carry out the optimization of the structure is the response surface. This method consists of adjusting a surface in which the minimum or maximum will later be sought depending on the optimizations' objective. In our case, we want students to see that there are other optimization objectives than cost, so we make them evaluate $\mathrm{CO}_{2}$ emissions and minimize them.

First, a design of experiments is carried out to obtain the parameters that are statistically representative. Then, the initial region is studied by blocking the value of the variables that are not going to be modified for the optimization, for this, a first order response surface is used. From this moment, the method of the rapid ascent/descent is used allowing us to approach in a fast way the optimal solution region. Finally, a second response surface design is made on which the optimum is calculated.

\subsection{Factorial design of experiments}

There are several methods of design of experiments [36], this type of design of experiments allows to identify the effect of the variables on the objective function. In this work, a factorial design of experiments has been used. This method is useful to students, not only for this study case, but also for any other optimization case. With this method they can detect what are the variables which are the ones that have a greater effect on the result of $\mathrm{CO}_{2}$ emissions and if the relation between them is relevant.

There are two types of factorial design, complete and fractional, depending on whether all possible combinations between the variables are studied or not. When considering five variables with two levels in the study, the number of combinations is 32 , which allows them all to be evaluated in a reasonable time, in case the number of variables is greater, a fractional design would have been chosen.

The factorial design of experiments is carried out by students in a computer practice guided by the professor. In this point the used two software first they use Cype concrete walls module [37] software to calculate wall possibilities, the they measure the solutions and introduce this data to excel to obtain the $\mathrm{CO}_{2}$ consumption. After that, they use Minitab to carry out the statistical analysis of the design of experiments.

\subsection{Maximum descent method}

In order to search for the optimum point we need to quickly approach the neighborhood of the optimum, for which we use the maximum descent method. First, it is verified if there is no curvature in the initial point, in this case, the region of the optimum is far from this point. On the contrary, if that curvature have existed it would indicate that we are already in the region of the optimum.

This method consists of taking sequential steps in the direction of the maximum slope line. The direction of the steps is obtained from the values of the coefficients $\left(\beta_{i}\right)$ of the first order approximation obtained from the response surface design made at the starting point. In case there is no restrictions, the neighborhood of the optimum will have been reached now when a turning point is found changing the trend from downward to upward. Once the inflection point has been reached, a new design of experiments is carried out where the curvature is again analyzed, predictably at this new point there will be curvature, which will indicate that we are in the environment of the optimum. In the case that the combinations of values can produce solutions that do not comply with the restrictions, they should be penalized, so that the objective function is unfavorable for them and they do not tend towards those solutions.

For this part of the exercise students uses the calculation software Cype [37] and Excel spreadsheet repeating the process of obtaining the reinforcement and measurements of the walls to introduce this to excel to obtain the $\mathrm{CO}^{2}$ emissions.

\subsection{Response Surface Methodology}

Once we are around the optimal point, we adjust a second order response surface, incorporating the curvature into the model [36]. By means of this surface we will be able to look for the point of smaller cost in the objective function optimizing this surface, that point, will give us some values of the studied variables that will correspond with the optimal combination.

The statistical part of this final phase that comprises the obtaining of the model of the second order and the optimal point is carried out with Minitab [38]. Once the point is obtained, student have to check that this is a possible solution introducing the solution obtained by the optimization in Cype [37]. 


\section{RESULTS}

In this study, the optimization of a five-meter high reinforced concrete wall has been carried out using the response surface method. The structure must comply with the Ultimate Limit States (ELU) corresponding to the Spanish Structural Concrete Instruction [29] and the stability conditions against overturning, slipping and sinking as established by the Technical Building Code [30] (CTE). The objective function corresponds to the direct cost of the units described in Table 3.

Table 3. Definition of the cost of the units of the objective function.

\begin{tabular}{lc}
\hline \multicolumn{1}{c}{ Unit } & Emisiones \\
\hline $\mathrm{kg}$ of Steel B500S & 3.02 \\
$\mathrm{~m}^{3}$ of concrete HA-30 & 224.94 \\
$\mathrm{~m}^{3}$ of excavation & 13.16 \\
$\mathrm{~m}^{3}$ of fill & 27.20 \\
$\mathrm{~m}^{2}$ of stem formwork & 31.66 \\
\hline
\end{tabular}

To perform the dimensioning the walls have been modeled by the program CYPE (Figure 2), this calculation is made per linear meter of wall. The measurement of the units of work and their corresponding unit costs provide the total emissions associated with the construction of the wall. The optimum of the problem will be that which meets the restrictions of both ELU and the conditions of overturning, sliding and sinking. In case one of the solutions does not comply with these restrictions it will not be discarded, since it is necessary to have data from a certain region, but the objective function will be penalized so that this solution has a higher associated cost.

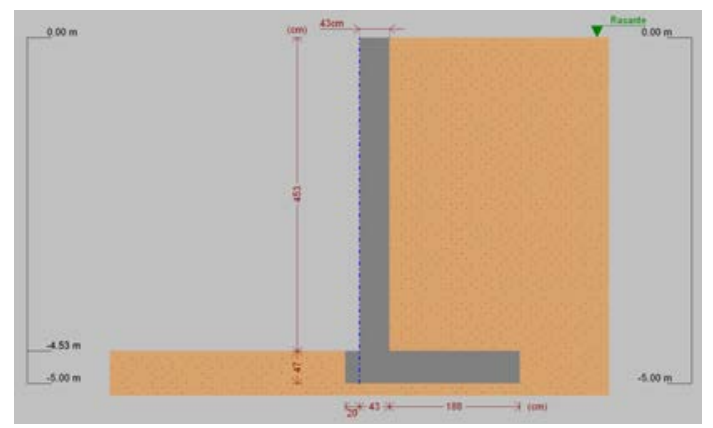

Figure 2. Wall computational model in CYPE software.

\subsection{Complete factorial design of experiments}

The design of experiments is carried out with the five factors observed in Figure 1. The influence of these factors on the objective function is unknown, so a two-level factorial experiment design is carried out. A complete design of experiments is chosen, which for the case studied are 32 experiments, in our case, evaluations of the structure. For this, the levels of Table 1 are defined.

Once the student introduce the data to Minitab and carry out the factorial design analysis they obtain the Pareto Frontier and the variables that are most significant. In this case, the most significant variable is the thickness of the wall, followed by the shoe edge, the length of the heel and the thickness of the earth. In addition, the effect of the length of the toe of the wall does not affect the objective function.

In this point, students are resolving a specific problem of wall optimization with a new approach. This gives students three main benefits. First, they are solving a real problem of wall optimization promoting transversal competence related to the analysis and resolution of problems. Second, they are using specific software not only for wall calculation, but also for statistical analysis. Indirectly they are seeing which parameters are those on which to focus the optimization on a reinforced concrete wall that is one of the most used structures in both civil and edification engineering.

Once this experiment is carried out, it is decided to perform the response surface method with the two variables that have the greatest influence on the objective function, being the wall thickness (e) and the heel length ( $\mathrm{t}$ ). The rest of the variables are blocked with the dimensions obtained from the study 
conducted by Yepes et al. [9]. The value of the blocked variables is $0.20 \mathrm{~m}$ for the length of the toe (p), $0.47 \mathrm{~m}$ for the edge of the shoe $(\mathrm{h})$ and $0 \mathrm{~m}$ for the value of the thickness of land in the intrados (et).

\subsection{Maximum descent method}

To carry out this method, first, we must check that the curvature in the study area does not exist. If there is curvature it would mean that we are already in a region close to the optimum. Therefore, an experiment design is made taking into account the two variables with which the study is carried out blocking all the others. For this phase of the study, the levels of 30 and $100 \mathrm{~cm}$ for the thickness of the wall (e) and 100 and $200 \mathrm{~cm}$ for the length of the heel (t) are considered.

Table 4. $P$ values obtained from the design of two-variable experiments with a central point.

\begin{tabular}{cc}
\hline Source & $\boldsymbol{P}$ value \\
\hline Model & 0.847 \\
Linear & 0.802 \\
$\mathrm{e}$ & 0.931 \\
$\mathrm{t}$ & 0.595 \\
Curvature & 0.695 \\
\hline
\end{tabular}

Table 4 shows the results of the factorial design of experiments with central point. It can be observed that there is no curvature, since the $p$ value is higher than 0.05 . Therefore, we apply the maximum descent method to find the region near the optimum. This method is a sequential process where the steps are proportional to the values of the regression coefficients $\left(\beta_{i}\right)$. To obtain these coefficients a first order surface is adjusted from the central point of the factorial design of experiments. The general equation of the first order-adjusted model is shown in (1). In our case, the result of this regression equation, considering only the variables e and $t$, is the one shown in (2).

$$
\begin{aligned}
& y=\beta_{0}+\sum_{i=1}^{k} \beta_{i} x_{i} \\
& \text { wall } \mathrm{CO}_{2}=2271+215 e-373 t
\end{aligned}
$$

Once the coefficients are obtained, the step size for the variable with the highest regression coefficient in absolute value must be decided. This will be called $\mathrm{x}_{\mathrm{j}}$ and the step size of this one is $\Delta \mathrm{x}_{\mathrm{j}}$. According to Montgomery [36], the step size will be determined by the experimenter knowledge of the process or other practical considerations. The procedure to obtain the value of the increment of the rest of variables is calculated as shown in (3).

$$
\Delta x_{i}=\frac{\beta_{i}}{\beta_{j}} \cdot \Delta x_{j}
$$

The maximum slope method starts at the center point of the adjusted first order surface and from this point, it moves in the direction of the maximum slope line obtained from the regression coefficients.

$$
\begin{aligned}
& \Delta \text { heel }=10 ; \beta_{\text {heel }}=-373 ; \beta_{\text {stem }}=215 \\
& \Delta \text { stem }=\frac{\beta_{\text {stem }}}{\beta_{\text {heel }}} \cdot \text { sheel }=-\frac{373}{215} \cdot 10=-5.76
\end{aligned}
$$

Making the increments of (4) and (5) the descent follows the line of maximum slope of the first order response surface. In each case, the objective function is penalized with the quotient between the value needed to comply with the restrictions $\mathrm{YEd}_{\mathrm{E}}$ and the value obtained from the calculation model $\mathrm{YRd}_{\mathrm{Rd}}$

$$
\text { wall } \mathrm{CO}_{2}=\text { wall } \mathrm{CO}_{2} \cdot \frac{\gamma_{E d}}{\gamma_{R d}} \quad ; \quad \frac{\gamma_{E d}}{\gamma_{R d}} \geq 1
$$

For each step, the value of the corrected $\mathrm{CO}_{2}$ cost is obtained from each evaluation of the structure and it is observed at what point the cost of the structure increases. As can be seen in Figure 4, there is a 
change in trend between step 7 and 8 , therefore the optimum will be in a region near the point corresponding to step 7 .

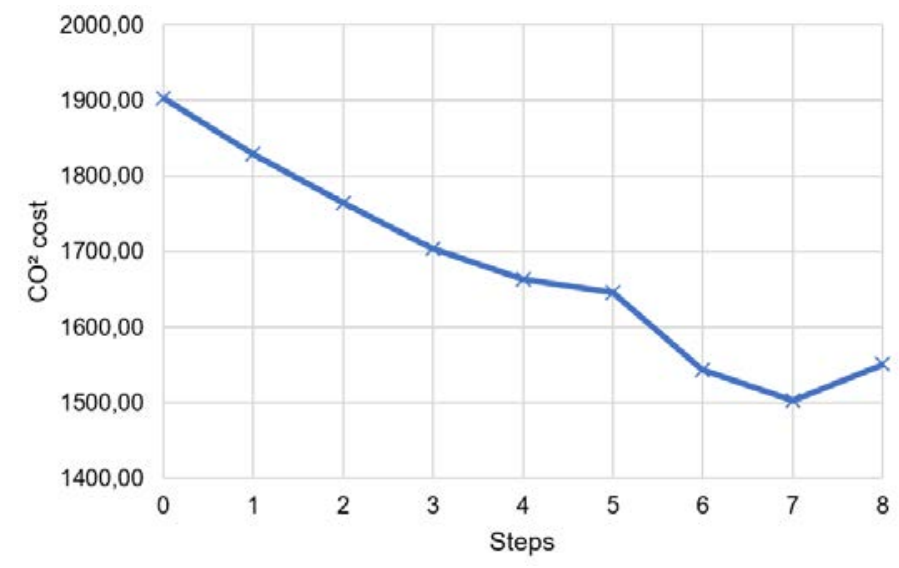

Figure 4. Graph of evolution of the cost of $\mathrm{CO}_{2}$ in the maximum descent method.

Once the point where the change of trend occurs is obtained, a new design of experiments is made with five central points [36], taking as a central point the inflection point and taking new levels for the variables. In this way, we delimit the region in which we will look for the optimum according to the results that have been obtained previously. The levels of the variables are 20 and 30 for the thickness of the elevation (e) and 215 and 225 for the length of the heel (t). Table 5 shows the result of the factorial design.

Table 5. Results of the $p$ value of the factorial design with 5 central points.

\begin{tabular}{cc}
\hline Source & $p$ value \\
\hline Model & 0.001 \\
Linear & 0.001 \\
$\mathrm{e}$ & 0.002 \\
$\mathrm{t}$ & 0.002 \\
Curvature & 0.004 \\
\hline
\end{tabular}

As can be seen as $p<0.05$ for the curvature, then we can assure that a first order model would not correctly describe the region of study. Therefore, we proceed to make the design of the second order response surface.

\subsection{Surface response methodology}

The second order response surface that will be later optimized is designed using the point corresponding to step number 7 as the central point and considering the new limits for variables $e$ and $t$ described in the previous section.

The objective is to optimize the surface to find the point that provides the optimal combination for variables values, and meet all the restrictions. Therefore, it is used (5) to obtain the corrected value of the cost in terms of $\mathrm{CO}_{2}$ consumption. This penalization will allow us to reach minimum emissions solutions that respects the safety restrictions imposed by the regulations.

The coefficient of determination $\mathrm{R}^{2}$ is $94.90 \%$, this means that quadratic model explains more than $90 \%$ of the variability in $\mathrm{CO}_{2}$ emissions. In Figure 5 it can be seen the contour graph of the second order model. In this point, students have used multiple statistical tools and are capable to replicate this method for every problem that the need to solve related with optimization. 


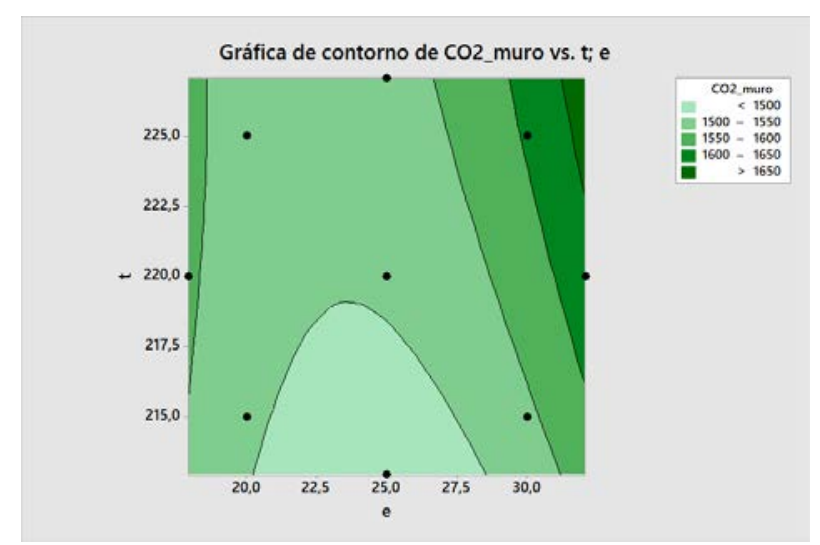

Figure 5. Second order model contour graph.

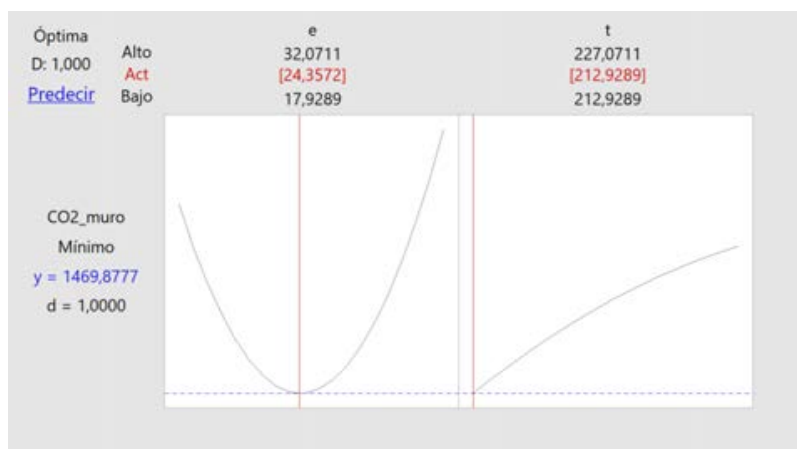

Figure 6. Optimization chart.

In this graph, the optimization is made to find the minimum as shown in Figure 6. It is obtained a value of $24.35 \mathrm{~cm}$ for the variable wall thickness and $212.9289 \mathrm{~cm}$ for the value of the length of the shoe with a cost in $\mathrm{CO}_{2}$ consumption of $1469.88 \mathrm{~kg}$ of $\mathrm{CO}_{2}$. These values cannot be executed with this level of accuracy in reality, so we rounded these values to 24.4 and $213 \mathrm{~cm}$ and evaluated the cost of this solution. The $\mathrm{CO}_{2}$ emissions obtained for this solution are $1479.32 \mathrm{~kg}$ of $\mathrm{CO}_{2}$. This step gives the students criteria for the definition of the structures, since they understand that the results obtained from an optimization are not always executable, it is necessary to look for the nearest one that gives the design a correct buildability.

\section{CONCLUSIONS}

This paper has described the application of the response surface methodology to optimize a reinforced concrete wall is order to reduce its $\mathrm{CO}_{2}$ emissions. This work is encompassed of the subject "predictive models of optimization of concrete structures". The aim of this project is to teach students how to reach optimum solutions applying both structural concepts and statistical tools in order to obtain an optimum reinforced concrete wall from a $\mathrm{CO}_{2}$ emissions point of view. This procedure allow postgraduate students to have tools to optimize structures applying new techniques that are out from the classical method of obtaining solutions through an iterative process of trial and error. As it can be seen in this work, the method allows obtaining the geometry of some variables focusing the search in varying the ones that have a greater influence in the objective function. Furthermore, as can be seen in this study, this procedure can be applied to not only cost optimization, but also $\mathrm{CO}_{2}$ or other objective functions. This study case resolution allow students to complement their lack of experience in structures optimization with surrogate models that will give an added value for their future incorporation into the labor market. Furthermore, as a result of applying this methodology to obtain an optimum reinforced concrete wall, student acquire different transversal competencies, such as design and project, critical thinking, analysis and problem solving or the use of specific instrumental. This works open the door to new research in education applying optimization techniques to reach optimum designs in other type of structures like bridges or other infrastructures like roads or other included inside the Civil Engineering field of knowledge. 


\section{ACKNOWLEDGEMENTS}

The authors acknowledge the support for the Ministry of Economy and Company and FEDER funding (Project BIA2017-85098-R).

\section{REFERENCES}

[1] V. Yepes, E. Pellicer, and A. J. Ortega, "Designing a Benchmark Indicator for Managerial Competences in Construction at the Graduate Level," Journal of Professional Issues in Engineering Education and Practice, vol. 138, no. 1, pp. 48-54, 2012.

[2] E. Pellicer, L. A. Sierra, and V. Yepes, "Appraisal of infrastructure sustainability by graduate students using an active-learning method," Journal of Cleaner Production, vol. 113, pp. 884-896, 2016.

[3] C. Torres-Machi, V. Yepes, A. Chamorro, and E. Pellicer, "Current models and practices of economic and environmental evaluation for sustainable network-level pavement management," Revista de la Construcción, vol. 13, no. 2, pp. 49-56, 2014.

[4] C. Torres-Machí, A. Carrión, V. Yepes, and E. Pellicer, "Employability of Graduate Students in Construction Management," Journal of Professional Issues in Engineering Education and Practice, vol. 139, no. 2, pp. 163-170, 2013.

[5] L. A. Sierra, E. Pellicer, and V. Yepes, "Social Sustainability in the Lifecycle of Chilean Public Infrastructure," Journal of Construction Engineering and Management, vol. 142, no. 5, p. 05015020 , 2016.

[6] E. Pellicer, V. Yepes, C.L. Correa, L.F. Alarcón, "Model for Systematic Innovation in Construction Companies," Journal of Construction Engineering and Management, vol. 140, no. 4, p. B4014001, 2014.

[7] World Commission, "Report of the World Commission on Environment and Development: Our Common Future."

[8] V. Penadés-Plà, D. Martínez-Muñoz, T. García-Segura, I. J. Navarro, and V. Yepes, "Environmental and Social Impact Assessment of Optimized Post-Tensioned Concrete Road Bridges," Sustainability, vol. 12, no. 10, p. 4265, May 2020.

[9] V. Yepes, J. Alcala, C. Perea, and F. González-Vidosa, "A parametric study of optimum earthretaining walls by simulated annealing," Engineering Structures, vol. 30, no. 3, pp. 821-830, 2008.

[10] F. Molina-Moreno, T. García-Segura, J. V. Martí, and V. Yepes, "Optimization of buttressed earthretaining walls using hybrid harmony search algorithms," Engineering Structures, vol. 134, pp. 205216, 2017.

[11] V. Yepes, F. Gonzalez-Vidosa, J. Alcala, and P. Villalba, "CO2-Optimization Design of Reinforced Concrete Retaining Walls Based on a VNS-Threshold Acceptance Strategy," Journal of Computing in Civil Engineering, vol. 26, no. 3, pp. 378-386, 2012.

[12] F. Molina-Moreno, J. V. Martí, and V. Yepes, "Carbon embodied optimization for buttressed earthretaining walls: Implications for low-carbon conceptual designs," Journal of Cleaner Production, vol. 164, pp. 872-884, 2017.

[13] J. J. Pons, V. Penadés-Plà, V. Yepes, and J. V. Martí, "Life cycle assessment of earth-retaining walls: An environmental comparison," Journal of Cleaner Production, vol. 192, pp. 411-420, Aug. 2018.

[14] P. Zastrow, F. Molina-Moreno, T. García-Segura, J. V. Martí, and V. Yepes, "Life cycle assessment of cost-optimized buttress earth-retaining walls: A parametric study," Journal of Cleaner Production, vol. 140, pp. 1037-1048, 2017.

[15] V. Penadés-Plà, T. García-Segura, J. V. Martí, and V. Yepes, "An optimization-LCA of a prestressed concrete precast bridge," Sustainability, vol. 10, no. 3, pp. 1-17, 2018.

[16] M. Z. Cohn and A. S. Dinovitzer, "Application of Structural Optimization," Journal of Structural Engineering, vol. 120, no. 2, pp. 617-650, Feb. 1994.

[17] C. Blum, J. Puchinger, G. R. Raidl, and A. Roli, "Hybrid metaheuristics in combinatorial optimization: A survey," Applied Soft Computing, vol. 11, no. 6, pp. 4135-4151, 2011.

[18] J. H. Holland, Adaptation in Natural and Artificial Systems. The MIT Press. 
[19] S. Kirkpatrick, C. D. Gelatt, and M. P. Vecchi, "Optimization by simulated annealing," Science (80)., vol. 220, no. 4598, pp. 671-680, 1983.

[20] I. Paya-Zaforteza, V. Yepes, F. González-Vidosa, and A. Hospitaler, "On the Weibull cost estimation of building frames designed by simulated annealing," Meccanica, vol. 45, no. 5, pp. 693-704, 2010.

[21] J. V. Martí, F. Gonzalez-Vidosa, V. Yepes, and J. Alcalá, "Design of prestressed concrete precast road bridges with hybrid simulated annealing," Engineering Structures, vol. 48, pp. 342-352, 2013.

[22] V. Yepes, M. Dasí-Gil, D. Martínez-Muñoz, V. J. López-Desfilis, and J. V. Martí, "Heuristic Techniques for the Design of Steel-Concrete Composite Pedestrian Bridges," Applied Sciences, vol. 9, no. 16, p. 3253, Aug. 2019.

[23] J. R. Martí-Vargas, F. J. Ferri, and V. Yepes, "Prediction of the transfer length of prestressing strands with neural networks," Computers and Concrete, vol. 12, no. 2, pp. 187-209, 2013.

[24] T. García-Segura, V. Yepes, and D. M. Frangopol, "Multi-objective design of post-tensioned concrete road bridges using artificial neural networks," Structural and Multidisciplinary Optimization, vol. 56, no. 1, pp. 139-150, 2017.

[25] K. N. Krishnanand and D. Ghose, "Glowworm swarm optimisation: a new method for optimising multi-modal functions," International Journal of Computational Intelligence Studies, vol. 1, no. 1, pp. 93-119, 2009.

[26] T. García-Segura, V. Yepes, J. V. Martí, and J. Alcalá, "Optimization of concrete l-beams using a new hybrid glowworm swarm algorithm," Latin American Journal of Solids and Structures, vol. 11, no. 7, pp. 1190-1205, 2014.

[27] V. Yepes, J. V. Martí, and T. García-Segura, "Cost and CO2 emission optimization of precastprestressed concrete U-beam road bridges by a hybrid glowworm swarm algorithm," Automation in Construction, vol. 49, no. PA, pp. 123-134, 2015.

[28] A. M. Law, Simulation modeling and analysis, 3rd ed. Boston: McGraw Hill, 2000.

[29] D. Martínez-Muñoz, J. V. Martí, and V. Yepes, "Steel-Concrete Composite Bridges: Design, Life Cycle Assessment, Maintenance, and Decision-Making," Advances in Civil Engineering, vol. 2020, p. 8823370, 2020.

[30] R. R. Barton and M. Meckesheimer, Metamodel-Based Simulation Optimization. 2006.

[31] T. García-Segura, V. Penadés-Plà, and V. Yepes, "Sustainable bridge design by metamodelassisted multi-objective optimization and decision-making under uncertainty," Journal of Cleaner Production, vol. 202, pp. 904-915, 2018.

[32] V. Penadés-plà, T. García-segura, and V. Yepes, "Accelerated optimization method for lowembodied energy concrete box- girder bridge design," Engineering Structures, vol. 179, no. June 2018, pp. 556-565, 2019.

[33] G. E. P. Box and K. B. Wilson, "On the Experimental Attainment of Optimum Conditions," Journal of the Royal Statistical Society: Series B (Methodological), vol. 13, pp. 1-45, 1951.

[34] M. T. Cihan, A. Güner, and N. Yüzer, "Response surfaces for compressive strength of concrete," Construction and Building Materials, vol. 40, pp. 763-774, 2013.

[35] J. J. Coz Diaz, P. J. Garcia-Nieto, F. P. Alvarez-Rabanall, M. Alonso-Martínez, J. DominguezHernandez, and J. M. Perez-Bella, "The use of response surface methodology to improve the thermal transmittance of lightweight concrete hollow bricks by FEM," Construction and Building Materials, vol. 52, pp. 331-344, 2014.

[36] D. C. Montgomery, Diseño y análisis de experimentos, $2^{\mathrm{a}}$ edición. México: México: Limusa-Wiley, cop. 2002. 2011., 2002.

[37] C. Ingenieros, "Muro en Ménsula de Hormigón Armado." .

[38] A. Alin, "Minitab," Wiley Interdisciplinary Reviews: Computational Statistics, vol. 2, no. 6, pp. 723 727, Nov. 2010. 